\title{
PENGARUH IMPLEMENTASI MANAJEMEN ASET TETAP DAN IMPLEMENTASI \\ PENGENDALIAN INTERNAL TERHADAP KUALITAS PELAPORAN KEUANGAN (Pada Pemkab/Pemkot Di Wilayah Pemerintahan Provinsi Jabar)
}

\author{
Yani Kurniasih, SE.,M.Ak \\ Program Studi Akuntansi - STIE Dr. KHez Muttaqien
}

\begin{abstract}
This research was conducted with the background of the phenomena that occur under audit results by the audit Board of the Republic of Indonesia that the poor quality of financial reporting, especially in local government both provincial and city/district. This research was conducted based on theories that already exist which later develoved into a research model in which the model in this study was designed to eximine the quality of financial reporting ands its relevance to the implementation of the asset management and implementation of the internal control.

This study aims to test and obtain empirical evidense of research in oder to obtain answers to the problems of research on how much influense of Implementation of the Asset Management and Implementation of the Internal control on the quality of financial Reporting. The benefits of research is to provide a scientific contribution to the science of public sector accounting and solve problems for local goverments in the implementations of task related to improving the quality of local government financial reporting.

This study used survey method with descriptive verification approach and type of causal research conducted at 28 local government both provincial and city/district.in west java. The unit of observation is the Departement of local Asset and finance management (DPKAD) Respondents in this study is the Head of departement, Secretary of departement, Head of Accounting and Head of Assets, Auditor of Inspektorat and Auditor of BPK RI representatives of western java. The data obtained through the questionnaiers were analyzed using the technique of component-Based Structural Equation Modeling (CBSEM) and processed using program Partial Least Square-Path Modeling (PLS-PM)

The result showed that : the Implementation of the asset management have a significant affect on the quality of financial reporting; the implementation of the internal control system have a significant effect on the quality of financial reporting;
\end{abstract}

Keywords : the Implementation of the Asset Management and The Implementation of the Internal Control system.

\section{PENDAHULUAN}

Aset/barang milik daerah merupakan salah satu alat penyelenggara roda pemerintahan guna mendukung pelayanan masyarakat/stakeholder. Ironisnya, walaupun memegang peran penting, barang milik daerah belum dikelola secara transparan dan akuntabel. Pengelolaan barang milik daerah sangat berarti bagi kewajaran laporan keuangan. Kesalahan dalam melakukan penilaian aset/barang milik daerah dapat mengakibatkan kesalahan material karena nilai yang diinvestasikan relatif signifikan, selain itu akan menghambat jalannya urusan pemerintahan sebagaimana yang diamanatkan oleh Undang-Undang No 32 Tahun 2004 tentang Pemerintahan Daerah dan PP No 27 Tahun 2004.
Saat ini sistem dan prosedur pencatatan aset tetap dan manajemen aset tetap daerah masih relatif lemah terutama inventarisasi aset tetap masih belum tertata rapi, kondisi aset tetap di lapangan menunjukkan masih banyak terdapat aset tetap yang tidak tercatat, tidak dilakukan pencatatan mengenai mutasi barang, dan tidak ada pengamanan fisik dan legalitas yang memadai. Kelemahan dalam penatausahaan maupun pencatatan/pelaporan atas Barang Milik Daerah (BMD) merupakan objek temuan rutin Badan Pemeriksa Keuangan (BPK) dalam Laporan Hasil Pemeriksan Keuangan (LHP)-nya atas Laporan Keuangan Pemerintah Daerah. Oleh karena itu BPK menetapkan Pemeriksaan 
atas manajemen aset menjadi salah satu tema pemeriksaan.

Adapun permasalahan yang menjadi pengecualian, diantaranya adalah dalam hal kelemahan pengendalian intern dan pengelolaan aset/barang milik daerah.
Berikut disajikan pengecualian atas pengendalian intern dan pengelolaan aset/barang milik daerah LKPD Kabupaten/kota dalam laporan hasil Pemeriksaan BPK RI semester II tahun 2014 sebagai berikut :

Tabel 1 Daftar Temuan - kelemahan SPI Pemeriksaan LKPD tahun 2011-2013

\begin{tabular}{|c|c|c|c|c|}
\hline No & Kelompok Temuan & $\sum_{2011}$ Kasus & $\sum_{2012}$ kasus & $\sum_{2013}$ kasus \\
\hline $\mathbf{I}$ & $\begin{array}{l}\text { Kelemahan Sistem Pengendalian Akuntansi } \\
\text { dan Pelaporan }\end{array}$ & 1.791 & 1.5861 & $\mathbf{1 . 8 4 0}$ \\
\hline 1 & $\begin{array}{l}\text { Pencatatan tidak/belum dilakukan atau tidak } \\
\text { akurat }\end{array}$ & 1.005 & 895 & 787 \\
\hline 2 & $\begin{array}{l}\text { Proses penyusiunan laporan tidak sesuai } \\
\text { ketentuan }\end{array}$ & 603 & 498 & 708 \\
\hline 3 & Entitas terlambat menyampaikan laporan & 13 & 16 & 4 \\
\hline 4 & $\begin{array}{l}\text { Sistem Informasi Akuntansi dan pelaporan } \\
\text { tidak memadai }\end{array}$ & 147 & 163 & 306 \\
\hline 5 & $\begin{array}{l}\text { Sistem Informasi akuntansi dan pelaporan } \\
\text { belum di dukung SDM yang memadai }\end{array}$ & 23 & 14 & 33 \\
\hline II & 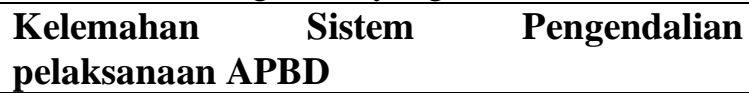 & 1.739 & 1.935 & 2.182 \\
\hline 1 & Perencanaan kegiatan tidak memadai & 577 & 617 & 720 \\
\hline 2 & $\begin{array}{l}\text { Mekanisme pemungutan, penyetoran dan } \\
\text { pelaporan serta penggunaan penerimaan daerah } \\
\text { dan bibah tidak sesuai ketentuan }\end{array}$ & 249 & 249 & 234 \\
\hline 3 & $\begin{array}{l}\text { Penyimpangan terhadap pearturan perundang- } \\
\text { undangan bid teknis ttg atau ketentuan intern } \\
\text { organisasi yang diperiksa tentang pendapatan } \\
\text { dan be;lanja pelaksanan belanja diluar } \\
97 \text { mekanisme APBD }\end{array}$ & 494 & 570 & 610 \\
\hline 4 & Pelaksanaan belanja diluar mekanisme APBD & 97 & 58 & 25 \\
\hline 5 & $\begin{array}{l}\text { Penetapan/pelaksanaan kebijakan tidak tepat } \\
\text { atau blm dilakukan berakibat hilangnya potensi } \\
\text { penerimaan/pendapatan }\end{array}$ & 237 & 324 & 385 \\
\hline 6 & $\begin{array}{l}\text { Penetapan/pelaksanaan kebijakan tidak teat } \\
\text { atau belum dilakukan berakibat peningkatan } \\
\text { biaya/belanja }\end{array}$ & 80 & 83 & 144 \\
\hline 7 & Lain-lain & 5 & 34 & 64 \\
\hline III & Kelemahan Struktur Pengendalian Intern & 839 & 891 & 1.111 \\
\hline 1 & $\begin{array}{l}\text { Entitas tidak memiliki SOP yang formal untuk } \\
\text { suatu prosedur atau keseluruhan prosedur }\end{array}$ & 509 & 485 & 491 \\
\hline 2 & $\begin{array}{l}\text { SOP yang ada pada entitas tidak berjalan secara } \\
\text { optimal atau tidak ditaati }\end{array}$ & 247 & 277 & 296 \\
\hline 3 & Entitas tidak memiliki satuan pengawas intern & 1 & 4 & 4 \\
\hline 4 & $\begin{array}{l}\text { Satuan pengawas intern yang ada tdk memadai } \\
\text { atau tdk berjalan optimal }\end{array}$ & 55 & 99 & 304 \\
\hline 5 & $\begin{array}{l}\text { Tidak ada pemisahan tugas dan fungsi yang } \\
\text { memadai }\end{array}$ & 25 & 26 & 16 \\
\hline 6 & Lain-lain & 2 & - & \\
\hline No & Kelompok Temuan & $\underset{2011}{\sum \text { Kasus }}$ & $\begin{array}{c}\sum \text { kasus } \\
2012\end{array}$ & $\sum_{2013}$ kasus \\
\hline & Total kelemahan SPI & 4.369 & 4.412 & 5.133 \\
\hline
\end{tabular}

Sumber : IHPS BPK RI semester II tahun 2014

Fenomena/fakta yang telah diuraikan di atas, dapat diketahui bahwa faktor yang menyebabkan ketidakwajaran yang berimbas pada ketidak-andalan Laporan Keuangan
Pemerintah Daerah diantaranya terletak pada efektivitas pengendalian intern atas pelaporan keuangan khususnya atas pengelolaan 
aset/barang milik daerah yang belum berjalan secara optimal.

Fakta tersebut sesuai dengan pernyataan Arens, Elder \& Beasley (2012:310) yang menyatakan "management has both a legal and professional responsibility to be sure that the information is fairly presented in accordance with reporting requirements of accounting framework such as GAAP and IFRS. The objective of effective internal control over financial reporting is to fulfill these financial reporting responsibilities". Dengan begitu, pemahaman akan pentingnya sistem pengendalian intern khususnya atas pengendalian manajemen aset tetap daerah perlu diperhatikan oleh pemerintah daerah sehingga diharapkan dapat mencapai kewajaran informasi aset tetap dalam neraca yang pada gilirannya akan menentukan tingkat keandalan informasi aset tetap. Hal ini sesuai dengan ungkapan kepala BPK RI

\section{Identifikasi Masalah:}

1. Seberapa besar implementasi manajemen aset tetap dan Implementasi Pengendalian Internal berpengaruh pada kualitas pelaporan keuangan SKPD secara parsial

2. Seberapa besar implementasi manajemen aset berpengaruh terhadap kualitas pelaporan keuangan SKPD secara simultan

3. Seberapa besar Implementasi pengendalian internal berpengaruh terhadap kualitas pelaporan keuangan SKPD secara simultan

\section{Tujuan Penelitian}

Tujuan dari penelitian ini adalah sebagai berikut :

1. Untuk menguji seberapa besar implementasi manajemen aset tetap

\section{TINJAUAN PUSTAKA DAN PENGEMBANGAN HIPOTESIS Manajemen Aset Tetap \\ Booz, Allen \& Hamilton}

mendefinisikan bahwa:

"Asset Manajement is management system to achive an organization business objective and cost effectively manage assets throut the life cycle of identification of neen for an asset, design and planning acquisition and as necessary, enhancement of assets, assets utilization including operating, maintence and improvements and disposal off assets".

\section{Pengendalian Internal}

Pada edisi yang baru ini, COSO (2013:3) mendefinisikan pengendalian internal sebagai berikut: "Internal control is yang menyatakan "keberadaan aset tetap sangat mempengaruhi kelancaran roda pemerintahan dan pembangunan. Oleh karena itu, sistem pengendalian intern atas manajemen/pengelolaan aset tetap daerah harus andal untuk mencegah penyimpangan yang dapat merugikan keuangan daerah".

Senada dengan pernyataan kepada BPK tersebut, Nunuy (2010:75) menyatakan " masih banyak kelemahan penatausahaan yang terjadi di pemerintah daerah. Contohnya antara lain adalah berkaitan dengan pengelolaan aset. Keandalan pengelolaan aset, dalam hal ini Pengendalian intern atas manajemen aset tetap berarti seluruh komponen pengendalian intern berupa lingkungan pengendalian, penilaian risiko, aktivitas pengendalian, informasi dan komunikasi, serta monitoring harus diterapkan dalam setiap siklus manajemen aset tetap.

berpengaruh terhadap Kualitas Pelaporan Keuangan pada pemda dan pemkot di wilayah pemerintahan Provinsi Jawa barat

2. Untuk menguji seberapa besar pengendalian internal atas pelaporan keuangan berpengaruh terhadap Kualitas Pelaporan Keuangan pada pemda dan pemkot di wilayah pemerintahan Provinsi Jawa barat

3. Untuk menguji seberapa besar implementasi manajemen aset, implementasi pengendalian internal terhadap terhadap Kualitas Pelaporan Keuangan pada pemda dan pemkot di wilayah pemerintahan Provinsi Jawa barat baik secara simultan maupun parsial

a process, effected by an entity's board of directors, manage-ment, and other personnel, designed to provide reasonable assurance regarding the achievement of objectives relating to operations, reporting, and compliance"

\section{Kualitas Pelaporan keuangan}

Kualitas Kualitas Laporan Keuangan adalah data dan informasi yang relevan berupa posisi keuangan dari transaksi yang terjadi sesuai dengan standar akuntansi yang berlaku selama satu periode pelaporan yang dibuat oleh entitas pelaporan yang digunakan dalam mengambil keputusan. Karakteristik kualitatif merupakan ciri khas yang membuat 
informasi dalam laporan keuangan berguna bagi pemakai. Terdapat empat karakteristik pokok menurut Pernyataan Standar
Akuntansi Keuangan No 1 (IAI, 2009) yaitu: dapat dipahami, relevan, keandalan dan dapat diperbandingkan.

\section{Pengaruh Manajemen Aset tetap terhadap kualitas Pelaporan keuangan}

Dian (2009) meneliti pengaruh implementasi manajemen aset tetap terhadap kewajaran aset tetap neraca Laporan Keuangan Pemerintah Daerah di wilayah provinsi jawa barat. Hasil penelitiannya menunjukan bahwa implementasi manajemen aset berpengaruh terhadap kewajaran aset di neraca.

Bertovic et. All mengembangkan model untuk pengelolaan aset yang dimiliki pemda. Model ini merupakan dasar pemikiran pengambilan keputusan mengenai akuisisi, penguasaan dan disposisi atas aset yang dimiliki pemda. Model ini dikembangkan dengan tujuan untuk melakukan pencatatan dan pengelolaan aset sesuai dengan standar sehingga dapat meningkatkan kualitas pelaporan keuangan pemda.

H1 : Implementasi manajemen aset berpengaruh positif dan signifikan terhadap Kualitas Pelaporan Keuangan

\section{Pengaruh manajemen aset berpengaruh terhadap Kualitas Pelaporan Keuangan}

Manajemen aset penting dalam mewujudkan laporan keuangan pemerintah daerah yang berkualitas seperti yang diungkapkan oleh Dadson dan ebenezer (2006) yaitu : Pelaporan keuangan menghasilkan sebuah laporan keuangan, beberapa faktor penentu untuk menghasilkan laporan keuangan yang berkualitas, adalah potensi SDM Good Government dan manajemen.

Quertani et all. Juga berpendapat bahwa suatu strategi manajemen informasi aset yang efektif dan terintegrasi perlu dikembangkan karena hal ini akan mempengaruhi performence perusahaan yang dicerminkan melalui penyajian laporan

Sistem Akuntansi yang lemah menyebabkan pengendalian intenal lemah dan pada akhirnya laporan keuangan yang dihasilkan juga kurang handal dan kurang relevan untuk pembuatan keputusan (Mardiasmo, 2004:34). Hal ini sejalan dengan pendapat Darise (2008:2) yang menyatakan bahwa keandalan (reliability) informasi keuangan yang disajikan dalam perhitungan anggaran juga sangat rendah karena sistem akuntansi yang diselenggarakan belum didasarkan pada standar akuntansi dan tidak didukung oleh perangkat data dan proses yang memadai.

$$
\text { Relevansi sistem akuntansi, }
$$

kompetensi aparatur, dan komponen komponen dalam sistem pengendalian inetrnal terhadap kualitas pelaporan keuangan adalah karena keandalan penyajian laporan keuangan merupakan salah satu tujuan dari penerapan penerapan sistem keuangan, dimana laporan keuangn merupakan hasil sebuah pelaporan keuangan. Dian (2009) meneliti pengaruh implementasi manajemen aset tetap terhadap kewajaran aset tetap neraca Laporan Keuangan Pemerintah Daerah di wilayah provinsi jawa barat. Hasil penelitiannya menunjukan bahwa implementasi manajemen aset berpengaruh terhadap kewajaran aset di neraca.

\section{H2 : Implementasi Pengendalian Internal berpengaruh positif dan signifikan terhadap Kualitas Pelaporan Keuangan}

pengendalian internal. Tujuan lainnya adalah efektifitas dan efisiensi operasi serta ketaatan terhadap hukum dan regulasi yang berlaku. Hal ini sesuai tujuan sistem pengendalian internal dan peran SPIP dalam pengelolaan keuangan negara (PP 60 Tahun 2008)

Hasil Penelitian dari peneliti sebelumnya disebutkan bahwa kualitas pelaporan juga dipengaruhi oleh efektifitas pengendalian internal organisasi. Peneliti yang dilakukan Petrovits, Shakespeare dan Shih (2010) ini ingin melihat penyebab dan dampak dari defisiensi pengendalian intern pada sektor nirlaba. Dari hasil pengolahan data statistik di dapatkan hasil bahwa masalah pengendalian intern pada organisasi memiliki hubungan positif dengan kondisi keuangan lemah, sedang tumbuh, lebih kompleks dan berukuran kecil.

\section{METODE PENELITIAN}

Populasi, Sampel, dan Teknik Pengambilan Sampel

Unit Analisis dalam penelitian ini adalah Pemda/Pemkot di wilayah pemerintahan
Provinsi Jawa barat. Populasi dalam penelitian ini adalah Pejabat Pengguna 
barang, Bagian Keuangan, Pengurus Barang/Aset, BPK RI Perwakilan jawa barat dan Auditor Inspektorat se provinsi Jabar. Sampel yang digunakan dalam penelitian ini sebanyak 140 responden dengan metode teknik component based Structural Equation Operasionalisasi Variabel

1) Manajemen Aset Tetap (X1)

Menurut PP no 27 tahun 2014 dimensi manajemen aset tetap sebagai berikut: 1) Perencanaan dan penganggaran \& pengadaan aset, 2) Penggunaan dan pemanfaatan \& penempatan, 3) penatausahaan, 4) Pengamanan dan pemeliharaan, 5) Penilaian, 6) Penghapusan, 7) Pemindah tanganan, 8) Pengendalian , 9) Pencatatan dan pelaporan

2) Pengendalian Internal $(X 2)$
Modeling (CBSEM) dan diolah menggunakan program Partial Least Square-Path Modeling (PLS-PM). Teknik pengumpulan data dalam penelitian ini menggunakan empat teknik yaitu Wawancara, Observasi, Kuesioner, dan Dokumentasi

Coso 2013, PP 60 tahun 2008 komponen Pengendalian Internal adalah: 1)lingkungan pengendalian , 2)Penilaian resiko, 3)Aktivitas pengendalian, 4) informasi dan komunikasi 5) Pemantauan.

3) Kualitas Pelaporan keuangan (y) Menurut PP 71 tahun 2010 karakteristik kualitas pelaporan keuangan yaitu: 1) relevan, 2) andal, 3) dapat dibandingkan, 4) dapat dipahami

HASIL PENELITIAN

Analisis Statisik Deskriptif

Tabel 2

Rekapitulasi Hasil Pengujian Reliabilitas

\begin{tabular}{|c|c|c|c|c|c|}
\hline Variabel & $\begin{array}{c}\text { Cronbach's } \\
\text { Alpha }\end{array}$ & $\begin{array}{c}\text { N of } \\
\text { Items }\end{array}$ & $\begin{array}{c}\text { Nilai } \\
\text { Kritis }\end{array}$ & Kesimpulan & Kriteria \\
\hline Manajemen Aset Tetap $\left(\mathbf{X}_{\mathbf{1}}\right)$ & 0,956 & 32 & 0,7 & Reliabel & Good \\
\hline Pengendalian Intern $\left(\mathbf{X}_{\mathbf{2}}\right)$ & 0,954 & 23 & 0,7 & Reliabel & Good \\
\hline $\begin{array}{c}\text { Kualitas Pelaporan Keuangan } \\
(\mathbf{Y})\end{array}$ & 0,893 & 13 & 0,7 & Reliabel & Good \\
\hline
\end{tabular}

Sumber: Hasil olah data menggunakan program SPSS 21.0

Pada tabel di atas, dapat dilihat bahwa ketiga variabel memiliki koefisien cronbach's alpha jauh lebih besar dari 0,7 sehingga dinyatakan reliabel. Dengan demikian dapat disimpulkan bahwa seluruh pertanyaan yang digunakan dalam penelitian sudah teruji kesahihan (validity) dan konsistensinya (reliability) untuk dapat digunakan sebagai alat ukur penelitian.

Dipetakan kedalam garis kontinum, persentase skor tersebut akan tampak sebagi berikut:

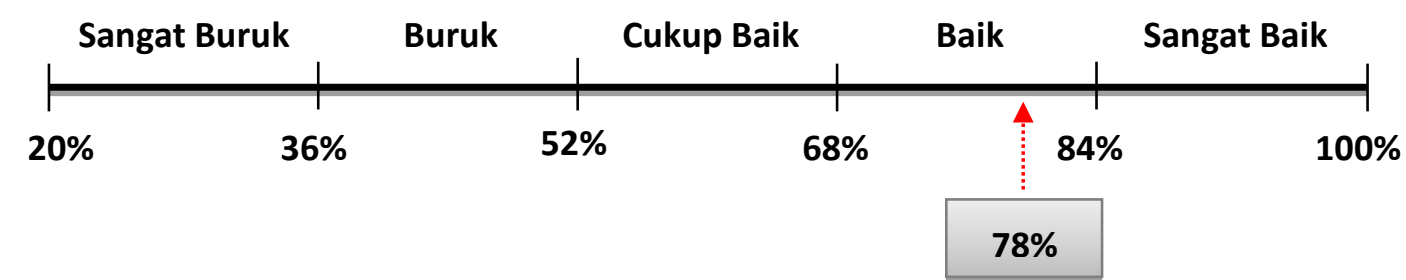

Gambar 1

Garis Kontinum Implementasi Manajemen Aset Tetap pada Pemda/ Pemkot di Wilayah Pemerintahan Provinsi Jawa Barat

Pada gambar garis kontinum di atas, tampak persentase skor sebesar $78 \%$ berada pada rentang persentase antara $68,1 \%-84 \%$ dan terkategorikan baik. Hasil tersebut menunjukan jika manajemen aset tetap pada Pemda/ Pemkot di Wilayah Pemerintahan Provinsi Jawa Barat sudah diimplemetasikan dengan baik.

Berikut adalah perhitungan indeks yang dilakukan penulis pada opini BPK RI selama kurun waktu lima tahun berturut-turut tahun 2011 sampai dengan tahun 2015 dengan membandingkan Implementasi Pengendalian Internal secara aktual olah data Kuesioner dan wawancara, interval nilai opini WTP di berikan skor 5, WDP di berikan skor 4, Discalimer diberikan skor 3 sehingga dapat diperoleh urutan Pemda/Pemkot di wilayah pemerintahan 
Provinsi jawa barat yang sering mendaptakan Opini WTP.

Tabel 3 indeks Opini BPK Atas Laporan Keuangan Pemerintah Daerah pada Pemerintah Provinsi/ Kabupaten/ Kota di Jawa Barat Tahun Anggaran 2011 s.d. 2015

\begin{tabular}{|c|c|c|c|c|c|c|c|}
\hline No. & Nama Entitas & 2011 & 2012 & 2013 & 2014 & 2015 & $\begin{array}{c}\text { Indek } \\
\text { S }\end{array}$ \\
\hline 1 & Provinsi Jawa Barat & 5 & 5 & 5 & 5 & 5 & 25 \\
\hline 2 & Kabupaten Bandung & 4 & 4 & 3 & 4 & 4 & 19 \\
\hline 3 & Kabupaten Bandung Barat & 4 & 4 & 4 & 4 & 4 & 20 \\
\hline 4 & Kabupaten Bekasi & 4 & 4 & 4 & 5 & 5 & 22 \\
\hline 5 & Kabupaten Bogor & 4 & 4 & 4 & 4 & 5 & 21 \\
\hline 6 & Kabupaten Ciamis & 4 & 4 & 5 & 5 & 5 & 23 \\
\hline 7 & Kabupaten Cianjur & 4 & 4 & 4 & 5 & 5 & 22 \\
\hline 8 & Kabupaten Cirebon & 4 & 4 & 4 & 4 & 5 & 21 \\
\hline 9 & Kabupaten Garut & 4 & 4 & 4 & 4 & 5 & 21 \\
\hline 10 & Kabupaten Indramayu & 4 & 4 & 3 & 4 & 5 & 20 \\
\hline 11 & Kabupaten Karawang & 4 & 4 & 4 & 4 & 5 & 21 \\
\hline 12 & Kabupaten Kuningan & 4 & 4 & 4 & 5 & 5 & 22 \\
\hline 13 & Kabupaten Majalengka & 4 & 4 & 5 & 5 & 5 & 23 \\
\hline 14 & Kabupaten Purwakarta & 4 & 4 & 4 & 4 & 5 & 21 \\
\hline 15 & Kabupaten Subang & 4 & 4 & 4 & 3 & 3 & 18 \\
\hline 16 & Kabupaten Sukabumi & 4 & 4 & 4 & 5 & 5 & 22 \\
\hline 17 & Kabupaten Sumedang & 4 & 4 & 4 & 5 & 5 & 22 \\
\hline 18 & Kabupaten Tasikmalaya & 4 & 4 & 4 & 5 & 5 & 22 \\
\hline 19 & Kota Bandung & 4 & 4 & 4 & 4 & 4 & 20 \\
\hline 20 & Kota Banjar & 5 & 5 & 5 & 5 & 5 & 25 \\
\hline 21 & Kota Bekasi & 4 & 4 & 4 & 4 & 5 & 21 \\
\hline 22 & Kota Bogor & 4 & 4 & 4 & 4 & 4 & 20 \\
\hline 23 & Kota Cimahi & 4 & 4 & 5 & 5 & 5 & 23 \\
\hline 24 & Kota Cirebon & 4 & 4 & 4 & 4 & 4 & 20 \\
\hline 25 & Kota Depok & 5 & 5 & 5 & 5 & 5 & 25 \\
\hline 26 & Kota Sukabumi & 4 & 4 & 4 & 5 & 5 & 22 \\
\hline 27 & Kota Tasikmalaya & 4 & 4 & 4 & 4 & 4 & 20 \\
\hline 28 & Kabupaten Pangandaran & 0 & 0 & 0 & 0 & 4 & 4 \\
\hline
\end{tabular}

Sumber: Hasil olah data opini BPK RI, 2016

Berdasarkan fenomena tersebut diatas kualitas pelaporan keuangan khususnya pemerintah daerah ternyata dipengaruhi oleh implementasi manajemen aset meskipun manajemen aset berada pada skor yang tinggi. Berikut presentase yang penulis lakukan pada Pemda/Pemkot diwilayah pemerintahan Provinsi Jawa Barat atas Opini BPK RI Tahun Anggaran 2011 s.d. 2015. Berdasarkan data hasil penyebaran kuesioner kepada responden, diperoleh tanggapan mengenai pengendalian intern yang diukur menggunakan 5 indikator dengan hasil sebagai berikut:

Tabel 5

Rekapitulasi Persentase Skor Tanggapan Responden Mengenai Implementasi Pengendalian Intern

\begin{tabular}{|c|l|c|c|c|c|}
\hline \multirow{2}{*}{ No. } & \multirow{2}{*}{ Indikator } & \multicolumn{2}{|c|}{ Indeks Skor } & \multirow{2}{*}{$\begin{array}{c}\text { Persentase } \\
\text { Skor }\end{array}$} & \multirow{2}{*}{ Kriteria } \\
\cline { 3 - 5 } & & Aktual & Ideal & & Baik \\
\hline \hline 1 & Lingkungan Pengendalian & 629 & 805 & $78,1 \%$ & Baik \\
\hline
\end{tabular}




\begin{tabular}{|c|c|c|c|c|c|}
\hline \multirow{2}{*}{ No. } & \multirow{2}{*}{ Indikator } & \multicolumn{2}{|c|}{ Indeks Skor } & \multirow{2}{*}{$\begin{array}{l}\text { Persentase } \\
\text { Skor }\end{array}$} & \multirow{2}{*}{ Kriteria } \\
\hline & & Aktual & Ideal & & \\
\hline 2 & Penilain Risiko & 355 & 460 & $77,2 \%$ & Baik \\
\hline 3 & Kegiatan Pengendalian & 710 & 920 & $77,2 \%$ & Baik \\
\hline 4 & Informasi dan Komunikasi & 183 & 230 & $79,6 \%$ & Baik \\
\hline 5 & Pemantauan & 192 & 230 & $83,5 \%$ & Baik \\
\hline \multicolumn{2}{|c|}{ Persentase Skor Dicapai } & 2069 & 2645 & $78,2 \%$ & Baik \\
\hline
\end{tabular}

Sumber: Hasil olah data kuesioner, 2016

Tabel di atas memberikan informasi mengenai rekapitulasi skor tanggapan responden mengenai implementasi pengendalian intern. Pada tabel di atas, dapat

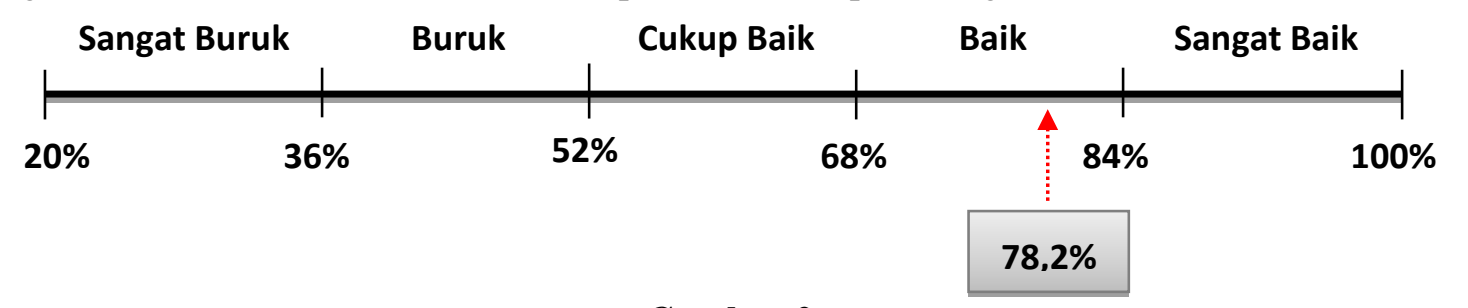

Gambar 2

Garis Kontinum Implementasi Pengendalian Intern pada Pemda/ Pemkot di Wilayah Pemerintahan Provinsi Jawa Barat

Pada gambar garis kontinum di atas, tampak jika persentase skor sebesar $78,2 \%$ berada pada rentang persentase antara $68,1 \%$ $84 \%$ dan terkategorikan baik. Hasil tersebut menunjukan bahwa pengendalian intern pada Pemda/ Pemkot di Wilayah Pemerintahan

dilihat persentase skor yang diperoleh adalah $78,2 \%$. Jika dipetakan kedalam garis kontinum, persentase skor tersebut akan tampak sebagi berikut:

Provinsi Jawa Barat sudah diimplemetasikan dengan baik.

Berikut tabel indeks skor Implementasi Pengendalian Internal secara aktual pada Pemda Pemkot di wilayah Pemerintahan Provinsi Jawa Barat sebagai berikut :

Tabel 6 Indeks skor Implementasi Pengendalian Internal

\begin{tabular}{|c|c|c|c|c|c|}
\hline \multirow{2}{*}{ No. } & \multirow{2}{*}{ Nama Entitas } & \multirow{2}{*}{$\begin{array}{c}\text { Indeks } \\
\text { opini } \\
\text { BPK } \\
\text { RI }\end{array}$} & \multicolumn{2}{|c|}{$\begin{array}{c}\text { Indeks Skor Pengendalian } \\
\text { Intern } \\
\end{array}$} & \multirow{2}{*}{$\%$} \\
\hline & & & Aktual & Ideal & \\
\hline 1 & Pemkab Bogor & 21 & 109 & 115 & $95 \%$ \\
\hline 2 & Provinsi jawa barat & 25 & 108 & 115 & $94 \%$ \\
\hline 3 & Pemkot Tasik malaya & 22 & 105 & 115 & $91 \%$ \\
\hline 4 & Pemkot Bekasi & 21 & 103 & 115 & $90 \%$ \\
\hline 5 & Pemkot Cirebon & 20 & 102 & 115 & $89 \%$ \\
\hline 6 & Pemkab Bandung & 19 & 102 & 115 & $89 \%$ \\
\hline 7 & Pemkot Sukabumi & 22 & 102 & 115 & $89 \%$ \\
\hline 8 & Pemkab Purwakarta & 21 & 102 & 115 & $89 \%$ \\
\hline 9 & Pemkab Bekasi & 22 & 100 & 115 & $87 \%$ \\
\hline 10 & Pemkab Ciamis & 23 & 96 & 115 & $83 \%$ \\
\hline 11 & Pemkot Cimahi & 23 & 95 & 115 & $83 \%$ \\
\hline 12 & Pemkot Depok & 25 & 95 & 115 & $83 \%$ \\
\hline 13 & Pemkot Bandung & 20 & 95 & 115 & $83 \%$ \\
\hline 14 & Pemkab Sukabumi & 22 & 93 & 115 & $81 \%$ \\
\hline 15 & Pemkab Bandung Barat & 20 & 92 & 115 & $80 \%$ \\
\hline 16 & Pemkab Garut & 21 & 89 & 115 & $77 \%$ \\
\hline
\end{tabular}




\begin{tabular}{|l|l|l|l|l|l|}
\hline 17 & Pemkab Cirebon & 21 & 87 & 115 & $76 \%$ \\
\hline 18 & Pemkab Karawang & 21 & 87 & 115 & $76 \%$ \\
\hline 19 & Pemkab cianjur & 22 & 82 & 115 & $71 \%$ \\
\hline 20 & Pemkab Sumedang & 22 & 76 & 115 & $66 \%$ \\
\hline 21 & Pemkot tasikmalaya & 20 & 73 & 115 & $63 \%$ \\
\hline 22 & Pemkot bogor & 20 & 65 & 115 & $57 \%$ \\
\hline 23 & Pemkab subang & 18 & 40 & 115 & $35 \%$ \\
\hline
\end{tabular}

Keterangan : Pemkot Banjar, Pemkab Indramayu, Pemkab kuningan, Kab. Pangandaran dan majalengka Kuesioner tidak kembali

Pemerintah Daerah yang memperoleh WTP mempunyai tingkat penerapan pengendalian internal cenderung tinggi. Begitu juga sebaliknya, walapun tidak menutup kemungkinan bahwa pemerintah daerah yang mempunyai tingkat penerapan pengendalian internal tinggi tetapi opininya WTP baru pada tahun 2015, seperti pada pemerintah kabupaten Bogor, tingginya skor penerapan pengendalian internal dimasing masing entitas pelaporan dan akuntansi yang dipertegas dengan terbitnya PP nomor 60 tahun 2008 akan tetapi masih banyak kelemahan dalam penerapannya (IHPS BPK RI semester II tahun 2015)

Tabel 7

Rekapitulasi Persentase Skor Tanggapan Responden Mengenai Kualitas Pelaporan Keuangan

\begin{tabular}{|c|l|c|c|c|c|}
\hline \multirow{2}{*}{ No. } & \multirow{2}{*}{ Indikator } & \multicolumn{2}{c|}{ Indeks Skor } & \multirow{2}{*}{$\begin{array}{c}\text { Persentase } \\
\text { Skor }\end{array}$} & \multirow{2}{*}{ Kriteria } \\
\cline { 3 - 4 } & & Aktual & Ideal & & \\
\hline \hline 1 & Relevan & 483 & 575 & $84,0 \%$ & Baik \\
\hline 2 & Andal & 261 & 345 & $75,7 \%$ & Baik \\
\hline 3 & Dapat Dibandingkan & 283 & 345 & $82,0 \%$ & Baik \\
\hline 4 & Dapat Dipahami & 190 & 230 & $82,6 \%$ & Baik \\
\hline \multicolumn{2}{l|}{ Persentase Skor Dicapai } & $\mathbf{1 2 1 7}$ & $\mathbf{1 4 9 5}$ & $\mathbf{8 1 , 4 \%}$ & Baik \\
\hline
\end{tabular}

Sumber: Hasil olah data kuesioner, 2016

Tabel di atas memberikan informasi mengenai rekapitulasi skor tanggapan responden mengenai pelaporan keuangan. Pada tabel di atas, dapat dilihat nilai persentase skor yang diperoleh adalah $81,4 \%$. Jika dipetakan kedalam gambar garis kontinum, persentase skor tersebut akan tampak sebagai berikut:

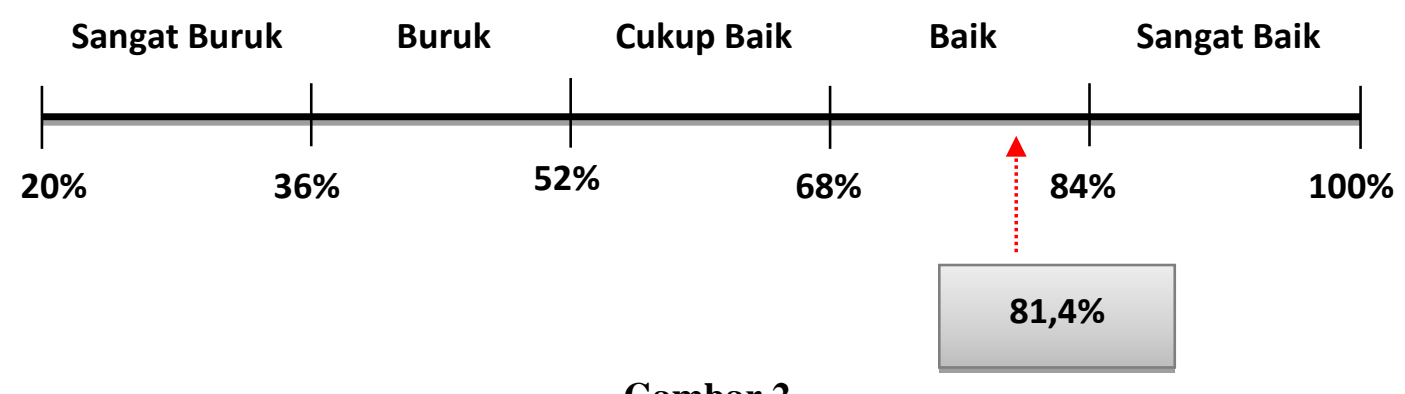

Gambar 2

Garis Kontinum Kualitas Pelaporan Keuangan pada Pemda/ Pemkot di Wilayah Pemerintahan Provinsi Jawa Barat

Pada gambar garis kontinum di atas, tampak jika persentase skor sebesar $81,4 \%$ berada pada rentang persentase antara $68,1 \%$ $84 \%$ dan terkategorikan baik. Hasil tersebut menunjukan bahwa pelaporan keuangan pada Pemda/ Pemkot di Wilayah Pemerintahan Provinsi Jawa Barat memiliki kualitas yang baik. 


\section{SIMPULAN}

1. Implementasi manajemen aset memiliki pengaruh positif yang signifikan terhadap kualitas pelaporan keuangan pada Pemda/Pemkot di Wilayah Pemerintahan Provinsi Jabar dengan kontribusi yang diberikan adalah sebesar $33,8 \%$, namun dengan tambahan informasi yang peneliti lakukan di lapangan menemukan permasalahan lain yang menjadi kelemahan implementasi manajemen aset tetap yaitu kelemahan dalam proses reklasifikasi aset yang terlambat dilakukan diatasi dengan perbaikan prosedur yaitu dokumen berita acara diberikan kepada Bidang akuntansi sebagai dasar reklasifikasi.

2. Implementasi Pengendalian Internal memiliki pengaruh positif yang signifikan terhadap kualitas pelaporan pada Pemda/ Pemkot di Wilayah Pemerintahan Prov Jabar dengan kontribusi yang diberikan adalah sebesar 42\%, namun dengan tambahan informasi yang peneliti lakukan di lapangan menemukan sumber permasalahan lain yang menjadi kelemahan bahwa mayoritas pemerintah daerah tidak memiliki perangkat hukum yang secara khusus mengatur sistem informasi manajemen aset tetap untuk meningkatkan pengendalian internal. Melakukan perbaikan prosedur dan dokumen yang dituangkan dalam Standart Operating Prosedure (SOP) agar dapat digunakan

\section{SARAN}

1. Meningkatkan kompetensi akuntan manajemen maupun tenaga akuntansi dengan cara mengikutsertakan pelatihan bintek atau pengembangan lainnya yang bertujuan untuk menambah pengetahuan dan keterampilan dibidang akuntansi agar mereka memahami proses penyusunan pelaporan keuangan mulai dari pencatatan transaksi sampai dengan penyusunan laporan keuangan sesuai PP 71/2010

2. Meningkatkan kompetensi akuntan manajemen dengan memiliki gelar Ak, CA dan sertifikasi lainnya yang terkait dengan akuntansi sektor publik.

3. Meningkatkan efektifitas penerapan sistem pengendalian intern dengan cara mematuhi PP No. 60 tahun 2008

4. Memberikan wewenang kepada pegawai yang tepat sesuai dengan tingkat tanggung jawabnya

5. Pimpinan perlu menegakkan tindakan disiplin yang tepat atas penyimpangan terhadap kebijakan dan prosedur serta pelanggaran aturan perilaku

6. Untuk mengatasi keterbatasan sumber daya yang ada dilakukan penambahan sebagai acuan dalam pelaksanaannya. Solusi utama dalam permasalahan ini yaitu pengembangan sistem Informasi tentang barang milik daerah khususnya manajemen aset tetap dilakukan secara terus menerus oleh Pemda/Pemkot di wilayah pemerintahan Provinsi Jawa Barat

3. Berdasarkan keseluruhan pemaparan analisis perhitungan statistik pada analisis model struktural dan pengujian hipotesis, maka dapat diambil kesimpulan bahwa secara simultan, Implementasi Manajemen aset tetap dan Implementasi pengendalian intern memberikan kontribusi pengaruh sebesar $75,8 \%$ terhadap kualitas pelaporan keuangan Pemda/Pemkot di Wilayah Pemerintahan Provinsi Jawa Barat, sedangkan sebanyak $24,2 \%$ sisanya merupakan kontribusi pengaruh yang diberikan oleh faktor lainnya yang tidak diteliti. Faktor lain yang memiliki kontribusi pengaruh diantara adalah kebijakan yang tidak sesuai dengan regulasi sehingga menciptakan rent seeking behavior. Salah satu contoh kasus pegawai yang mutasi ke dinas lain Aset yang dipinjam pakai tidak diserahkan kepada dinas yang melakukan identifikasi dan pencatatan (dinas asal) karena dianggap sudah mengeluarkan biaya perawatan diluar anggaran yang disediakan.

fungsi staff fixed asset pada struktur organisasi Bidang Aset, Staff fixed asset bertugas melakukan pengelolaan dan pengawasan aset tetap.

7. Untuk pengawasan aset tetap perlu dilakukan rekonsiliasi aset tetap secara berkala dan menempelkan nomor aset tetap secara rutin (tag) sesuai dengan nomor aset yang ada di daftar aset tetap.

8. Membuat perbaikan prosedur agar bagian accounting ikut menyaksikan proses penjualan aset tetap. Belum ada prosedur untuk transaksi pemusnahan aset tetap oleh karena itu dilakukan penambahan prosedur dan penambahan dokumen untuk pemusnahan aset tetap agar transaksi ini tercatat. Dan kemudian prosedur depresiasi aset tetap, dokumen rekap depresiasi ditambahkan dengan kolom otorisasi, Untuk pencocokkan daftar depresiasi dengan akun depresiasi sebelumnya dilakukan satu tahun sekali, maka dilakukan perbaikan prosedur agar pencocokkan dilakukan satu bulan sekali. 


\section{DAFTAR PUSTAKA}

Arens. Alvin A., Elder, Randal J., Beasley, Mark S. 2006. Auditing And assurance services: An Integrated Approach. Prentice Hall

Arikunto, Suharsimi. 2006. Prosedur Penelitian (Suatu Pendekatan Praktik). Edisi Revisi VI. Penerbit Rineka Cipta. Jakarta

Badan Pemeriksaan Keuangan. 2015. Laporan Hasil Pemeriksaan BPK RI Nomor:

48.B/LHP/XVIII.BDG/05/2015.

Bertovic, Kaganova, Rutledge 2004, Aset Manajemen Model, Local GovernmentReformn Project, USAID

Booz, Allen \& Hamilton. 2013. Strategy and technology of management

Bergmann, Andreas. 2009. Public Sector Financial Management. Pearson Education Limited, Prentice Hall, Englad

Bellkaoui, Ahmed Riahi., 2004, Accounting theory 5 Th Edition, High Holborn House 50-51 Bedford Row, London WCIR 4 LR, Thomson Learning

Bidgoli, Hossein., 2004, the Internet Ensyclopedia Volume 2, Hoboiken, New Jersey : John Wiley \& Sons

Coraline, Byant; White Louise, 1987, Manajmenen Pembangunan untuk Negara Berkembang, Terjemahan, Jakarta:LP3ES.

Dadson , james, and ebenezer, Kobina 2006. Optimizing Land asset Management in Ghana a shared Responsibility and recipe for good Governance, Shaping in change XXIII Congress, Munich, Germany.

Danylo, N.H and Lemer. APWA task Force on Asset Management reveals reliminary findings to members, APWA Reporter, December 1998/January 1999

Doli D. Siregar. 2004. Management Aset : Strategi Penataan Konsep Pembanguan Berkelanjutan Secara Nasional Dalam Konteks Kpala Daerah Sebagai CEO's Pada era Globalisasi dan Otonomi daerah. Satyagama Graha Tara. Jakarta. PT Gramedia Utama.

Darise, Nurlan. 2008. Akuntansi Keuangan Daerah (Akuntansi Sektor Publik). Cetakan I. Jakarta: PT Indeks.

Doyle, Ge, \& Mcvay. 2007. Accruals Quality and Internal Control Over Financial
Reporting. The Accounting Review Vol.82 No.5:1141-1170

Gelinas, Jr Ulrich J., Dull, Richard B., Wheeler, Patrick R., 2012, Accounting Information System, 5191, Natorp Boulevard Mason, USA : South Western Cengange Learning

Hevesi, G. Alan. 2005. Standard for Internal Control in new York State Government. www.osc.state.ny.us.

Hall, James A. 2011. Accounting Information Sistem, seven edition, South Western Publishing Co.p.11-14

Hidayat, M. D. 2011. Manajemen Aset (Privat dan Publik). Yogyakarta: Laksbang PRESSindo Yogyakarta.

Hadinata, A. 2011. Bahan Ajar Manajemen Aset. Jakarta: Sekolah Tinggi Akuntansi Negara.

Kieso, Weygandt, Warfied. 2002. Intermediate Accounting.John Wiley and son

Local Government Victoria. 2004. Asset Management Policy, Strategy and Plan. Melbourne: Department for Victorian Communities

Lu, Y. 2011. Public Asset Management : Empirical Evidence from the State Governments in the United States. Florida: Florida Atlantic University

M. Grubisic, M. Nušinovic and G. Roje. 2009. Towards Efficient Public Sector Asset Management Financial Theory and Practice 33 (3) 329-362 Portugal: Comparative International Governmental Accounting Research

Mardiasmo. 2004. Akuntasi Sektor Publik. Andi: Jogyakarta

Nunuy Nur Afiah. 2010. Tinjauan Permasalahan Pengelolaan Keuangan di Pemerintahan Indonesia: Telah Kritis Siklus Pengelolaan Keuangan Daerah. Jurnal Ekonomi dan Bisnis Terapan Vo.6 No.2:68-81

Pemerintah Republik Indonesia. 2014. Peraturan Pemerintah Nomor 27 Tahun 2014. Jakarta: Pemerintah Republik Indonesia

Pemerintah Republik Indonesia. 2010. Peraturan Pemerintah Nomor 71 Tahun 2010 tentang Standar Akuntansi Pemerintah. Jakarta: Pemerintah Republik Indonesia

Petrovits, Christine, shakespearl \& shih, Aimee 2010. The Causes and 
consequences of Internal Control Problems In Nonprofit Organizations

Public Company Accounting Oversight Board (PCAOB). 2004. An audit of internal control over of financial Reporting Performed in Conjuction with an Audit of Financial Statements. Wasington DC: PCAOB Release.

Romney,Marshall., B and Steinbart, Paul J., 2012, Accounting Information System Quality as the Ground for quality Business Reporting, IADIS International Conference ecommerce, ISBN: 972-8924-23-2

Sekaran, U. (2006). Research Method for Business, Metode Penelitian Bisnis. Salemba Empat: Jakarta.

Ulrich, Dave, 1995, Human Resources Champions (the Next Agenda for Adding Value)., Michigan: University Of Michigan.

Shiper, K., and vincent, L., 2003, Earning Quality, Accounting Horizons, Supplemen 97-110

Sugiyono. 2009. Metode Penelitian Pendidikan Pendekatan Kuantitatif, Kualitatif dan R\&D. Alfabeta: Bandung.
Sugiama, A. 2012. Handout Penilaian aset. Bandung Polban

Suwardjono. 2005. Teori Akuntansi: Perekayasaan Pelaporan Keuangan.Edisi keiga. BPFE, Yogyakarta.

Setiyawati. 2016. The effect Of Management Accountant's Competence, Organizational Commitment, The Implementation of the Asset Management and the Implementation of the Internal Control sistem on the quality of Financial Reporting and It's Impact on the Financial Accountability. International Journal Of Business and Management Invention Vo. 2 Iss.11:19-27

IAI. 2009. Pernyataan Standar Akuntansi Keuangan No 1. Jakarta

The Institute of Asset Management. 2012. Asset Management - an anatomy. London. www.theIAM.org/AMA.

William S, Hopwood., \& Bodnar, George H., 2005, Accounting Informations System, 11 edition, Upper Saddle River New jersey 07458:Pearson/Prentice Hall 